\title{
Functional Outcome in Late Adolescence/ Early Adulthood of Patients With Autism Spectrum Disorder and Its Relationships With Parental Burnout and Depression: Multi-center, Cross-sectional Study
}

\section{Meryem Ozlem KUTUK ( $\nabla$ drozlemina@gmail.com )}

Department of Child and Adolescent Psychiatry, Baskent University Faculty of Medicine, Adana Dr. Turgut Noyan Medical and Research Center, Adana

Ali Evren TUFAN

Department of Child and Adolescent Psychiatry, Bolu Abant Izzet Baysal University, Faculty of Medicine, Bolu

Fethiye KILICASLAN

Department of Child and Adolescent Psychiatry, Harran University, Faculty of Medicine, Sanliurfa

Pinar VURAL

Department of Child and Adolescent Psychiatry, Uludağ University, Faculty of Medicine, Bursa

\section{Cem GOKCEN}

Department of Child and Adolescent Psychiatry, Gaziantep University, Faculty of Medicine, Gaziantep

\section{Sevay Alsen GUNEY}

Department of Child and Adolescent Psychiatry, Dokuz Eylul University Faculty of Medicine, Izmir

\section{Bahtım KUTUK}

Department of Psychology, Ege University, Izmir

\section{Gonca OZYURT}

Department of Child and Adolescent Psychiatry, İzmir Katip Çelebi University, Faculty of Medicine, Izmir

\section{Neslihan INAL}

Department of Child and Adolescent Psychiatry, Dokuz Eylul University Faculty of Medicine, Izmir

\section{Tuba MUTLUER}

Department of Child and Adolescent Psychiatry, Koc University Faculty of Medicine, Istanbul

\section{Eren Yavuz ACIKALIN}

Department of Child and Adolescent Psychiatry, Koc University Faculty of Medicine, Istanbul

\section{Fadime Hande OZER}

Department of Psychology, Hasan Kalyoncu University, Gaziantep

\section{Esma Nur PAMUK}

Department of Psychology, Çağ University, Mersin

\section{Seyma Celikcan YESILMESE}

Department of Psychology, Çağ University, Mersin

\section{Mehmet KARADAG}

Department of Child and Adolescent Psychiatry, Gaziantep University, Faculty of Medicine, Gaziantep

\section{Zehra TOPAL}

Department of Child and Adolescent Psychiatry, Gaziantep University, Faculty of Medicine, Gaziantep

\section{Cilem BILGINER}

Department of Child and Adolescent Psychiatry, Karadeniz Technical University, Faculty of Medicine, Trabzon 


\section{Nilfer SAHIN}

Department of Child and Adolescent Psychiatry, Muğla Sıtkı Koçman University, Faculty of Medicine

\section{Oznur BILAC}

Department of Child and Adolescent Psychiatry, Manisa Celal Bayar University, Faculty of Medicine, Manisa

\section{Hasan KANDEMIR}

Department of Child and Adolescent Psychiatry, Manisa Celal Bayar University, Faculty of Medicine, Manisa

\section{Eyup Sabri ERCAN}

Department of Child and Adolescent Psychiatry, Ege University, Faculty of Medicine, İzmir

\section{Tugba Eseroglu SOYLEMEZ}

Department of Child and Adolescent Psychiatry, Baskent University, Faculty of Medicine, Istanbul Medical Research and Practice Center, Istanbul

\section{Sadettin Burak ACIKEL}

Department of Child and Adolescent Psychiatry, Konya City Training and Research Hospital, Konya

\section{Gulen Guler AKSU}

Department of Child and Adolescent Psychiatry, Mersin University, Faculty of Medicine, Mersin

\section{Pelin DAG}

Department of Child and Adolescent Psychiatry, Mersin University, Faculty of Medicine, Mersin

\section{Fevziye TOROS}

Department of Child and Adolescent Psychiatry, Mersin University, Faculty of Medicine, Mersin

\section{Caner MUTLU}

Department of Child and Adolescent Psychiatry, Basaksehir Cam and Sakura City Hospital, Istanbul

\section{Omer KARDAS}

Department of Child and Adolescent Psychiatry, Dicle University, Faculty of Medicine, Diyarbakır

\section{Burcu KARDAS}

Department of Child and Adolescent Psychiatry, Gazi Yaşargil Education and Research Hospital, Diyarbakır

\section{Suleyman KIZILDAG}

Department of Child and Adolescent Psychiatry, Dicle University, Faculty of Medicine, Diyarbakır

\section{Esra DEMIRCI}

Department of Child and Adolescent Psychiatry, Erciyes University, Faculty of Medicine, Kayseri

\section{Sevgi OZMEN}

Department of Child and Adolescent Psychiatry, Erciyes University, Faculty of Medicine, Kayseri

\section{Leyla SEVICIN}

Department of Child and Adolescent Psychiatry, Erciyes University, Faculty of Medicine, Kayseri

\section{Yuksel Sumeyra KARAGOZ}

Department of Child and Adolescent Psychiatry, Training and Research Hospital, Erzurum

\section{Umit ISIK}

Department of Child and Adolescent Psychiatry, Süleyman Demirel University, Faculty of Medicine, Isparta

\section{Evrim AKTEPE}

Department of Child and Adolescent Psychiatry, Süleyman Demirel University, Faculty of Medicine, Isparta

\section{Hatice ALTUN}

Department of Child and Adolescent Psychiatry, Kahramanmaras Sütçü Imam University, Faculty of Medicine, Kahramanmaras

\section{Cigdem YEKTAS}

Department of Child and Adolescent Psychiatry, Üsküdar University, Istanbul

\section{Berna Polat TUYSUZ}


Department of Child and Adolescent Psychiatry, Sanliurfa Education and Research Hospital, Sanliurfa Ahmet BUBER

Department of Child and Adolescent Psychiatry, Pamukkale University, Faculty of Medicine, Denizli

\section{Mehmet Akif CANSIZ}

Department of Child and Adolescent Psychiatry, Yozgat Bozok University, Faculty of Medicine, Yozgat

\section{Hakan OGUTLU}

Department of Child and Adolescent Psychiatry, Ankara City Hospital, Ankara

\section{Safak ERAY}

Department of Child and Adolescent Psychiatry, Uludağ University, Faculty of Medicine, Bursa

\section{Hande Ayraler TANER}

Department of Child and Adolescent Psychiatry, Baskent University, Medical Faculty, Ankara

\section{Ebru ALTINTAS}

Department of Psychiatry, Baskent University, Medical Faculty, Adana

\section{Ozgur KUTUK}

Department of Medical Genetics, Baskent University Faculty of Medicine, Adana Dr. Turgut Noyan Medical and Research Center, Adana

\section{Research Article}

Keywords: ASD, Adulthood, Burnout, Parents, Adult ASD

Posted Date: January 10th, 2022

DOI: https://doi.org/10.21203/rs.3.rs-1204237/v1

License: (c) (i) This work is licensed under a Creative Commons Attribution 4.0 International License. Read Full License 


\section{Abstract}

The aim of this study is to determine functioning of adults with Autism Spectrum Disorders (ASDs) diagnosed in childhood and also depression and burnout levels among their parents. 261 adults with ASDs and their parents were recruited for the study. Both parents completed the Beck Depression and Maslach Burnout Inventories and reported the functioning of their adult offspring with ASDs. Only $5.4 \%$ of our sample reported "good" or "very good" outcome. The most common psychiatric comorbidities were intellectual disabilities and attention-deficit/ hyperactivity disorder. Maternal burnout and depression scores were significantly elevated compared to those of fathers. There is an undeniable urgent need for more research to identify the needs of adults and families suffering from ASD.

\section{Introduction}

Autism Spectrum Disorder (ASD) is a neurodevelopmental disorder that presents with communication and social impairments, limited interests and repetitive actions, and problems with sensory integration ${ }^{1}$. Although genetic factors are important, the symptoms are thought to arise from a complex interplay of genetic, epigenetic, and environmental factors $^{2,3}$. Latest estimates of prevalence suggest that ASD may affect one out of every forty children in the USA ${ }^{4}$ with a male-to-female ratio of 2.5:1, while the average worldwide frequency ranges from 1.8-7.2 per ten thousand ${ }^{5,6}$.

Based on frequency of children with ASD, it is expected that approximately 700,000 adults aged 65 and older in the next 20 years will have ASD in the US. Similar percentages will be expected all over the world, which is not ready based on the needs of the disorder ${ }^{7}$.

The transition from adolescence to adulthood is also difficult for neurotypical youth and their family members. However, for individuals with ASD and their families this transition may be more complicated and stressful ${ }^{8,9}$. As children age; parents' concerns focus on the future and issues of guardianship, education, day services/employment, independent living, transition planning, health and safety, social outlets and financial security come to the forefront ${ }^{10-}$ ${ }^{12}$. Blacher, Kraemer and Howell ${ }^{13}$ suggested that parents of young adults with ASD were more concerned about the transitional processes compared to others whose children had Down syndrome or Cerebral Palsy. Also, mothers with lower education, male children, and older children may be significantly more anxious about the future ${ }^{14}$. Specifically, parents' concerns on independent living of their children with ASD and their future well-being increase as they grow into adulthood ${ }^{12,15}$ affecting their mental health. Studies addressing parents of adults with ASD found that behavior problems, psychiatric morbidity, gender of the child with diagnosis, poor physical health, and social impairments were associated with reduced quality of life, problems in intra-familial relationships, and elevated symptoms of depression and anxiety among parents as well as children ${ }^{16-19}$. A recent study by Hoyle and colleagues ${ }^{20}$ found that mothers were under elevated risk of psychopathology even when their adult child with developmental disability had achieved independent living.

Studies on adults with ASD from Turkey are limited, although interest in their functional outcomes and comorbidities are increasing ${ }^{21}$. In the first study, ${ }^{22,23}, 21$ patients with ASDs with an average age of 20.9 years (range $=16.0-36.0$ ) and with IQ $\geq 50$ were evaluated. In this study; $20.0 \%$ of the patients were reported to have symptomatic improvement during puberty, while rate of comorbid psychotic disorders was $4.8 \%$. Gormez ${ }^{24}$ evaluated parenting burden among 101 Turkish adults with intellectual disabilities (IDs); of which 31.7 percent also had ASDs. In the study, elevated caregiving burden was associated with ASD, behavioral problems, and caregivers' higher education level. Gormez and colleagues ${ }^{25}$ also evaluated a large group $(n=771)$ of adults with IDs and reported that $50.1 \%$ had psychiatric symptoms, while rate of challenging behaviors was $36.4 \%$. Challenging behaviors were predicted by the presence of 
ASD, and $64.7 \%$ reported barriers to receiving appropriate care. None of those studies evaluated functional outcome with operationally defined criteria and all were limited to single centers.

Specialized Child and Adolescent Psychiatry Departments in Turkey have been in operation since 1990 26,27 and children initially diagnosed with ASD have been getting older. However, no study until now has concentrated on how Turkish late adolescents/ early adults diagnosed with ASD in their childhood function and the problems experienced by their parents. Therefore, the goals of this study were;

a. to evaluate the sociodemographic features and functional outcomes of Turkish late adolescents/ early adults with ASD diagnosed in childhood,

b. to determine predictors of favourable functional outcomes,

c. to assess self-reported burnout and depression levels among their parents and to determine factors associated with clinicially significant depression levels among parents.

\section{Results}

\section{Sociodemographic characteristics of adults with ASDs and their families}

Two hundred and sixty-one adults with ASDs (86.2\% male) with a mean age of 21.4 (SD = 2.9, Range: 18.0-38.0) years could be contacted. Mean ages of mothers and fathers were 47.8 (SD = 5.7, Range: 35.0-69.0) and 52.3 (SD = 6.6, Range: 36.0-76.0) years; respectively. Thirteen individuals with ASD (5.0\%) lost their fathers. Sociodemographic characteristics of the parents are shown in Table 1. 
Table 1

Sociodemographic characteristics of parents of Turkish adults with ASD

\begin{tabular}{|c|c|c|c|}
\hline & & $\mathbf{N}$ & $\%$ \\
\hline \multirow[t]{5}{*}{ Maternal education } & Illiterate & 7 & 2.7 \\
\hline & Literate & 7 & 2.7 \\
\hline & Primary school & 117 & 45.0 \\
\hline & High school & 62 & 23.8 \\
\hline & University & 67 & 25.0 \\
\hline \multirow[t]{6}{*}{ Maternal vocation } & House wife & 172 & 70.8 \\
\hline & Public servant & 32 & 13.2 \\
\hline & Worker & 5 & 2.1 \\
\hline & Manager & 1 & 0.4 \\
\hline & Artisan & 11 & 4.5 \\
\hline & Retired & 22 & 9.1 \\
\hline \multirow[t]{5}{*}{ Paternal education } & Illiterate & 0 & 0.0 \\
\hline & Literate & 4 & 1.6 \\
\hline & Primary education & 87 & 34.8 \\
\hline & High school & 68 & 27.2 \\
\hline & University & 91 & 36.4 \\
\hline \multirow[t]{6}{*}{ Paternal vocation } & Unemployed & 6 & 2.6 \\
\hline & Public servant & 60 & 26.0 \\
\hline & Worker & 36 & 15.6 \\
\hline & Manager & 4 & 1.7 \\
\hline & Artisan & 66 & 28.6 \\
\hline & Retired & 59 & 25.5 \\
\hline
\end{tabular}

Eighty-nine mothers (34.1\%) and sixty-two of the fathers (25.0\%) reported chronic physical disorders requiring treatment in themselves. Most common disorder in mothers was hypertension $(n=35,39.3 \%)$ while diabetes $(n=23$, $40.4 \%$ ) was the most common disorder among fathers. Forty-seven of the mothers (17.9\%) and fifteen of the fathers (6.0\%) reported that they were receiving treatment for psychopathology in themselves. Most common diagnosis was major depression disorder in both ( $n=35,74.5 \%$ of mothers and $n=10,66.7 \%$ of fathers). A sibling of twenty-one adults with ASD (8.3\%) was also receiving treatment for psychopathology (mostly depression, $n=8,38.1 \%$ ). The majority of adults were living in intact, nuclear families $(n=218,83.5 \%)$ and most parents $(n=159,61.2 \%)$ complained of not having enough time for themselves or their spouses. 


\section{Age at diagnosis, comorbidities and educational/ health services received by adults with ASDs}

Median age at diagnosis was $36.0(\mathrm{IQR}=24.0$, Range= 6.0-144.0) months while median age for starting special education was $40.0(\mathrm{IQR}=30.0$, Range= 12.0-216.0) months among adults with ASD. The median time for special education was $15.0(\mathrm{IQR}=5.0$, Range= 1.0 - 33.0) years and the majority $(n=191,73.2 \%)$ were continuing special education services at the time of the study.

Twenty-seven (10.3\%) of the adults with ASD could atttend nation-wide school placement examinations with appropriate modifications. Almost half $(n=127,48.8 \%)$ completed high-school and five $(1.9 \%)$ completed their university educations.

Over half of the adults with ASD ( $n=147,56.3 \%)$ previously received other psychiatric/ neurodevelopmental diagnoses in addition to their ASD. Most common previous diagnoses were IDs ( $n=92,35.1 \%)$, attention deficit/ hyperactivity disorder (ADHD, $n=53,20.2 \%)$ and behavior problems/ oppositionality $(n=9,3.4 \%)$. Over sixty percent $(n=161,61.7 \%)$ were followed by psychiatrists at the time of the study and 137 (53.5\%) were currently diagnosed with a comorbid disorder (Table 2).

Table 2

Comorbid diagnoses of Turkish adults with ASDs during their participation in the study (according to their current psychiatrists)

\begin{tabular}{|lll|}
\hline Diagnosis & N & $\%$ \\
\hline Intellectual disabilities & 77 & 29.5 \\
\hline Attention Deficit/ Hyperactivity Disorder & 42 & 16.1 \\
\hline Conduct disorder & 19 & 7.3 \\
\hline Obsessive Compulsive Disorder & 7 & 2.7 \\
\hline Major Depressive Disorder & 6 & 2.3 \\
\hline Generalized Anxiety Disorder & 4 & 1.5 \\
\hline Bipolar Disorder & 2 & 0.8 \\
\hline
\end{tabular}

One adult with ASD (0.4\%) smoked and drank alcohol regularly. Sixty-eight (26.1\%) participants displayed self injurious behavior at least once. Suicide attempt has been reported in six participants (2.3\%). In five of these cases (83.3\%) psychiatric comorbidity was present.

The majority of adults with ASD ( $n=189,72.7 \%)$ were receiving psychopharmacological treatment while enrolled in the study. Twenty-eight (14.8\%) continued the medication prescribed by their child/adolescent psychiatrist without being followed up by any psychiatrist.

Most commonly used agents were antipsychotics ( $n=165,63.2 \%)$, mood stabilizers/ antiepileptics $(n=49,18.8 \%)$ and antidepressants $(n=29,11.1 \%)$. Eighty-four adults with ASD $(32.2 \%)$ had chronic physical disorders requiring treatment. The most common of these disorders were epilepsy $(n=50,19.2 \%)$, obesity $(n=9,3.5 \%)$ and autoimmune thyroiditis $(n=4,1.5 \%) .94$ participants $(36.0 \%)$ were admitted to hospital at least once for health problems. 
Hospitalizations were mostly due to physical disorders ( $n=87,92.6 \%)$, while seven participants $(7.4 \%)$ were admitted for psychiatric disorders.

Parents of thirty-seven adults (14.2\%) previously sought complementary and alternative treatment methods (CAM). The most common methods were hyperbaric oxygent therapy $(n=16,44.4 \%)$, dietary modifications $(n=6,16.7 \%)$ and hippotherapy ( $n=4,11.1 \%)$.

\section{Language abilities, social skills and legal problems of adults with ASDs}

At the study enrollment, almost half of the adults with ASD ( $n=112,42.9 \%)$ were able to construct $\geq 3$-word sentences while almost one-third $(n=80,30.7 \%)$ was mutistic. Improper behaviors such as touching/masturbation in community were reported by parents of 45 adults (17.2\%). Ninety-nine participants (37.9\%) harmed another at least once due to rage attacks and nine were previously involved in legal proceedings (3.4\%) due to social communication problems and narrowly focused interests.

More than one fourth of adults with ASD $(n=74,28.4 \%)$ could communicate with phone and $21.8 \%(n=57)$ had social media accounts that they managed with some help from their parents. Thirty-seven adults with ASD (14.2\%) had friends which they socialized with $\geq 3$ hours/week and $3.4 \%(n=9)$ had experienced romantic relationships lasting a few months with a member of the opposite sex. None had stable, long-term relationships and none were married at the time of the study.

\section{Independent living, self-care, transportation and employment of adults with ASDs}

Most of the participants with ASD ( $n=257,98.5 \%)$ were still living with their parents while four $(1.5 \%)$ were living in nursing homes. Majority were continent $(n=233,89.3 \%)$ while less than half $(n=120,46.0 \%)$ could carry out self-care by themselves. Fifty-six (21.5\%) could go shopping for themselves at nearby malls, while twenty-nine (11.1\%) could manage travelling alone in their city by public transport. Less than one tenth $(n=16,6.1 \%)$ could manage inter-city travel by bus/train or airplane, while only three (1.1\%) passed the examination for their drivers' license. Less than onetenth $(n=24,9.2 \%)$ of adults with ASD worked at a job for at least a month. The median duration of work was 12.0 (IQR = 21.0, Range: 1.0-48.0) months. None of the adults with ASD could partake in the obligatory military service in Turkey.

\section{Classification and predictors of "good"/ "very good" functional outcome of adults with ASD}

A composite measure of overall social functioning in our sample was calculated according to Howlin et al. (2004) ${ }^{38}$. As a result, the majority of ASD subjects in our sample was classified as having "very poor" ( $n=196,75.1 \%)$ or "poor" ( $n=$ $31,11.9 \%)$ outcome. Only twenty participants (7.7\%) were classified as having "fair" outcome. Rates for "good" and "very good" outcome were $2.7 \%$ each $(n=7)$. Logistic regression was used to evaluate predictors of "good" or "very good outcome" in the sample and age at diagnosis, duration of special education, age at speech onset, presence of IDs, comorbid psychopathology, epilepsy, maternal and paternal higher education (high-school or above) were entered as predictors. The overall model was significant $(\mathrm{AIC}=93.8, \mathrm{BIC}=123.0, \chi 2(8)=12.5, \mathrm{p}=0.13$ ) and may explain $17.3 \%$ variability in the outcome (Nagelkerke R2 $=0.173$, Table 3 ). 
Table 3

Predictors of "good" or "very good" outcome among Turkish adults with Autism Spectrum Disorders.

\begin{tabular}{|llllll|}
\hline Predictor & Odds Ratio & $\mathbf{9 5 \%}$ Confidence Interval & $\mathbf{p}$ & VIF & Tolerance \\
\hline Intercept & 0.6 & $0.0-8.3$ & 0.675 & - \\
\hline Age at diagnosis (months) & 1.0 & $1.0-1.0$ & 0.845 & 1.1 & 0.9 \\
\hline Age at speech onset (months) & 1.0 & $1.0-1.0$ & 0.653 & 1.1 & 1.0 \\
\hline Duration of special education (yrs) & 1.2 & $1.0-1.3$ & 0.022 & 1.1 & 0.9 \\
\hline No IDs & 3.3 & $0.4-28.1$ & 0.267 & 1.0 & 1.0 \\
\hline No psychiatric comorbidity & 1.8 & $0.4-7.4$ & 0.435 & 1.1 & 1.0 \\
\hline No epilepsy & 2.5 & $0.3-21.2$ & 0.402 & 1.0 & 1.0 \\
\hline Maternal higher education & 1.0 & $0.3-3.8$ & 0.979 & 1.2 & 0.9 \\
\hline Paternal higher education & 4.4 & $0.8-23.4$ & 0.083 & 1.1 & 0.9 \\
\hline VIF: Variance Inflation Factor, yrs: years & & & & \\
\hline
\end{tabular}

Duration of special education was the only significant predictor in the analysis, although offspring of fathers with higher education also tended to have more favourable outcomes. The model could correctly classify all of the participants without "good" or "very good" outcomes and none of those with "good" and "very good" outcomes (Accuracy $=0.93$, AUC $=0.80)$.

\section{Depression levels of parents of adults with ASDs and associated factors}

The mean BDI scores of mothers and fathers were $11.7(\mathrm{SD}=8.9)$ and $8.8(\mathrm{SD}=9.1)$; respectively. Maternal BDI scores were found to be significantly higher compared to fathers ( $t[261]=2.8, p=0.001$, $t$-test for paired samples). Maternal BDI scores did not differ significantly according to comorbid psychopathology among their offspring at the time of the study $\left(12.8 \pm 9.1\right.$ vs. $\left.11.2 \pm 8.8, t[235]=-1.3, p=0.186, p^{\prime}=0.372\right)$, epilepsy $(13.7 \pm 9.4$ vs. $11.2 \pm 8.7, t[235]=-1.7, p=$ $\left.0.100, p^{\prime}=0.300\right)$ or presence of "good" / "very good outcome" $(10.6 \pm 12.6$ vs. $11.7 \pm 8.6, t[235]=0.5, p=0.636$, $\left.p^{\prime}=0.636\right)$. However, mothers of adults with ASD and IDs reported significantly elevated BDI scores (13.7 \pm 8.8 vs. $10.8 \pm$ $8.8, t[235]=-2.4, p=0.02,95 \% \mathrm{Cl}=-5.4--0.5, p^{\prime}=0.08$ with Holm-Bonferroni correction). Comorbid psychopathology, epilepsy, IDs and "good"/ "very good" outcome did not significantly affect paternal BDI scores (p between 0.169 - 0.941 , independent samples t test).

When a cut-off score of 17 or higher was taken as a measure of "clinically significant depressive symptoms" as proposed by Hisli ${ }^{29} ; 22.9 \%$ of mothers $(n=60)$ and $10.7 \%$ of fathers $(n=28)$ were found to have significant depression. Clinically significant depression symptoms in mothers were related to incontinence according to the bivariate analysis $\left(\chi 2=8.4, p=0.004, P h i=0.19, p^{\prime}=0.012\right)$, lack of sparetime for themselves and their spouses $(\chi 2=$ $\left.22.8, p=0.000, P h i=0.31, p^{\prime}=0.000\right)$, and clinically significant depressive symptoms in fathers $(\chi 2=5.9, p=0.015, P h i$ $\left.=0.16, p^{\prime}=0.03\right)$. Mothers of mutistic adults also tended to be report clinically significant depressive symptoms $(\chi 2=$ $3.0, p=0.08$, Cramer's $v=0.15, p^{\prime}=0.08$ ). Clinically significant depressive symptoms in fathers were significantly associated with lack of education of their children $\left(\chi 2=8.1, p=0.004\right.$, Cramer's $\left.V=0.19, p^{\prime}=0.012\right)$, a history of hospitalization of their child $\left(\chi 2=6.4, p=0.012\right.$, Phi $\left.=0.16, p^{\prime}=0.024\right)$ and clinically significant depression symptoms among their wives $\left(\chi 2=5.9, p=0.015\right.$, Phi $\left.=0.16, p^{\prime}=0.024\right)$. 


\section{Burnout levels of parents of adults with ASD and associated factors}

Maternal/paternal burnout levels of Turkish adults with ASD are shown in Table 4. Mothers' emotional exhaustion and total burnout scores were found to be significantly elevated compared to fathers. Maternal MBI scores did not differ significantly according to outcome or comorbid psychopathology. However, mothers of adults with ASD who also had IDs (19.3 \pm 8.5 vs. $15.1 \pm 10.1, t[235]=-3.1, p=0.002,95 \% \mathrm{Cl}=-6.9--1.5, p^{\prime}=0.012$ for emotional exhaustion and $28.1 \pm$ 11.8 vs. $23.0 \pm 13.0, t[234]=-2.8, p=0.005,95 \% \mathrm{Cl}=-8.6--1.6, p^{\prime}=0.025$ for total burnout) and epilepsy $(19.1 \pm 10.5$ vs. $15.8 \pm 9.6, t[235]=-2.0, p=0.044,95 \% \mathrm{Cl}=-6.5--0.1, p^{\prime}=0.160$ for emotional exhaustion) reported greater burnout. Paternal burnout levels were not affected by outcome, comorbid psychopathology, and epilepsy. However, fathers of adults with ASD and IDs reported greater levels of total burnout $(26.3 \pm 12.6$ vs. $20.5 \pm 12.9, t[149]=-2.5, p=0.014$, $\left.95 \% \mathrm{Cl}=-10.3--1.2, \mathrm{p}^{\prime}=0.056\right)$.

Table 4

Burnout levels of mothers and fathers of Turkish adults with ASDs

\begin{tabular}{|llllll|}
\hline Mean (SD) & $\begin{array}{l}\text { Mothers } \\
(\mathbf{n = 2 6 1 )}\end{array}$ & $\begin{array}{l}\text { Father } \\
(\mathbf{n}=\mathbf{2 6 1})\end{array}$ & $\mathbf{t}$ & $\mathbf{9 5 \%} \mathbf{C l}$ & $\mathbf{p}$ \\
\hline MBI- Depersonalization & $7.1(5.6)$ & $6.5(5.3)$ & 1.7 & $-0.1-1.4$ & 0.102 \\
\hline MBI- Emotional exhaustion & $15.7(10.2)$ & $12.6(8.9)$ & 3.3 & $1.5-4.5$ & 0.000 \\
\hline MBI- Personal accomplishment & $8.8(7.2)$ & $9.4(7.8)$ & 1.1 & $-1.6-0.5$ & 0.293 \\
\hline MBI- Total & $24.2(13.7)$ & $21.9(13.2)$ & 2.4 & $0.3-4.4$ & 0.025 \\
\hline SD: Standard Deviation, MBI: Maslach Burnout Inventory, Cl: Confidence Interval & \\
\hline
\end{tabular}

\section{Discussion}

This multi-center, cross-sectional study aimed to evaluate functional outcomes among adults with ASD, parental depressive symptoms and burnout levels. Majority of adults with ASD in our sample had "poor" or "very poor" outcome according to Howlin et al (2004) criteria while only $5.4 \%$ were classified as having "good" or "very good" outcome ${ }^{38}$. Duration of special education was the only significant predictor of favourable outcome while offspring of fathers with higher levels of education also tended to fare better. Mothers were significantly more depressed compared to fathers. More than one fifth of mothers and one tenth of fathers reported significant levels of depression. Significant maternal depression was associated with greater severity of ASD symptoms, lack of spare time, and paternal depression. Clinically significant depression symptoms among fathers were associated with lack of formal education for their children, a history of hospitalization among children and maternal depression. Mothers especially those with offspring who also had IDs reported elevated levels burnout compared to fathers.

Initially described disorders of infancy and often conceptualized as childhood disorders, ASD are now known to be lifelong conditions $38,39,18$. Children, who were diagnosed with autism in the late 1990 s and early 2000 , began to be adults. This transition is challenging not only for individuals with ASD but also for their parents ${ }^{8,40-42}$. The majority of available studies on adults with ASD and their parents were conducted among western samples and no study up to now evaluated functioning of adults with ASD and depression and burnout levels of their parents in Turkey.

Caring for individuals with ASD from the time of diagnosis onward is a demanding process and parents must balance parenting roles within their marriage. They also act as co-therapists emphasizing positive behavior, while educating 
relatives, schools, and teachers on the nature of ASD, advocate for their children's rights and with the transition to adulthood must address problems such as guardianship, higher education, social/ romantic relationships of their children, financial security, independent living and housing ${ }^{10}$. These lead them to experience elevated levels of stress and burnout.

Mothers of children with ASD are the primary caregivers experiencing elevated stress and this may contribute to the development of maternal psychopathology ${ }^{36}, 43$. Most of the past studies supported that mothers of children with ASD experience elevated burden and depression in comparison to fathers ${ }^{44}$. Previous studies from Turkey have shown that both parents of children with disabilities experiences elevated stress, depression and burnout, but this was greater in mothers compared to fathers ${ }^{36,45}$. In a study conducted among parents of Turkish adults with IDs, Gormez ${ }^{24}$ reported that elevated caregiving burden was associated with comorbid ASD, behavioral problems and caregivers' higher education levels. Supporting those views self-reported depression and burnout levels in our study were also significantly elevated in mothers compared to fathers although we could not find an effect of parental education. This difference may be due to heterogenous nature of patients in the Gormez study ${ }^{24}$, use of differing instruments (e.g. Zarit Caregiving Burden Interview vs. MBI) or sampling methods. Effects of parental education on burnout and depression may be evaluated with further studies.

Previous studies suggested that mothers with lower education, with male and/ or older children with ASD, and with children having behavior problems as well as psychiatric comorbidity, physical disorders and social impairments may be more depressed and anxious ${ }^{14,16-19}$. The presence of functional speech in children, higher paternal/ maternal education levels, access to specialized schooling for children, greater family income, lack of comorbidities among children, and using medications to manage ASD symptoms may also reduce parenting stress $30,32,46-48$. Depression and anxiety in one parent, especially for mothers may spill-over to other family members ${ }^{49}$. Previous reports suggest that the rate of clinically significant depression in parents raising children with ASD ranged from $12.5-34.2 \%{ }^{50-54}$. A recent meta-analysis reported the depression rate in parents of children with ASD as $31.0 \%{ }^{53}$. Supporting those views, we found that more than one fifth of mothers and one tenth of fathers in our sample reported significant levels of depression. Significant depression in mothers was related to incontinence in children, lack of spare time, and depression in their husbands. Mothers of adults with ASD and comorbid IDs also tended to report increased depression. Clinically significant depression symptoms in fathers were related to lack of formal education for their children, a history of hospitalization among children, and significant depression symptoms among mothers. Mothers described increased emotional fatigue and total burnout compared to fathers. Presence of IDs and epilepsy in adult offspring with ASD also increased maternal burnout while there was a signal that paternal burnout may also be affected by presence of IDs. Those results support and extend the results of previous studies and may suggest that parenting stress, burnout and depression may continue over long term for parents of children with ASD. Depression in parent dyads may also spillover from mothers to fathers or vice versa ${ }^{32}$. Further studies on Turkish samples with ASD and their parents as they age may be required to evaluate the temporal changes in those constructs.

ASD is also associated with elevated rates of comorbid physical disorders, psychopathology as well as early mortality 55-57. Lifetime rates for comorbid psychopathology among adults with ASD may vary between $69.0-79.0 \% 16,56$. Most common psychiatric/ neurodevelopmental comorbidities found in previous studies were anxiety disorders (40.0 84.0\%), MDD (31.0 - 77.0\%), oppositional defiant disorder (ODD, 53.0\%), and ADHD (42.0 - 68.0\%). A systematic review found that $61.5 \%$ of adults with ASD were treated with psychotropic medications. Most commonly used medications were atypical anti-psychotics followed by stimulant/nonstimulant ADHD medicine and antidepressants ${ }^{58}$. In another study, $64.1 \%$ of adults were prescribed at least one psychotropic medication, $46.4 \%$ took two or more psychotropic medications. Furthermore, twenty-two percent of these polypharmacy samples were not being followed by 
a psychiatrist ${ }^{59}$. Similar to those studies, more than half of adults with ASD in our sample also had a comorbid psychopathology. The majority were given psychopharmacological treatment, mostly with antipsychotics. However, differing from those studies most of the patients in our sample had comorbid ADHD and rates of mood and anxiety disorders were lower. This discrepancy may reflect the fact that they were being followed by psychiatrists who tend to evaluate symptoms with unstructured clinical interviews rather than using specific instruments (e.g., PAS-ADD Checklist). In addition, the parents reported that their psychiatrists, most of whom lacked expertise in neurodevelopmental disorders consulted with the parents rather than observing the behavioral changes among their offspring with ASD, especially those without functional speech. The diagnoses of clinicians may also be affected by diagnostic overshadowing ${ }^{60}$. Further studies using structured interviews modified for ASD may be required to evaluate comorbid diagnoses among Turkish adults with ASD. Also, almost one-third of our patients was mutistic and with a similar rate of comorbid MR/ID that may limit their ability to express and desribe inner experience. On the other hand, several symptoms of ASD may mimic those of depression ${ }^{61,62}$ and autism is linked to alexithymia, which may affect presentation of depression ${ }^{38,63-66}$. The rate of ADHD detected in our adult cohort was comparable to the rate in children with ASD. This may reflect homotypic temporal continuity of ADHD comorbidity as other studies have previously mentioned ${ }^{67-72}$.

ASD among adults may be associated with medical complications and those may be found among 25 - 50 percent of patients ${ }^{73,74}$. Research is relatively new in this field; however, studies indicate an increased risk for multiple conditions such as problems in vision/ hearing, diabetes, cardiovascular disorders, obesity, tyroid diseases, sleep problems and gastrointestinal disorders ${ }^{65,75-81}$. Lifetime rates for epilepsy among patients with ASD vary between $2.7-40.0 \%$ 82-87. Supporting to these results, in our sample, eighty-four participants were found to have chronic organic diseases requiring treatment. The most common of these diseases were epilepsy, obesity, and autoimmune thyroiditis. These results demonstrate that there is a need to develop improved treatment options and quality of care in this population 41,77

After high school, enrollment in tertiary education or finding employment are the most common steps. Those steps into adulthood can be challenging for those with ASD ${ }^{88,89}$. Previous studies reported limited access to tertiary education $(28.0 \%)^{88}$ and frequent problems in adapting to environment in those with access to tertiary education ${ }^{90}$. In Canada, Eaves and $\mathrm{Ho}^{78}$ analyzed adults with ASD and reported that $45.0 \%$ had never been employed. In an older study from the US ${ }^{91}$ only $27.0 \%$ of adults with ASD displayed some level of work/employment. In another study with adults in Australia, it was found that only a minority were engaged in paid employment ${ }^{92}$. Our results are consistent with those studies. The majority of our sample were still receiving special education at the time when they took part in the study, less than half completed high school and less than two percent could complete tertiary education. Additionally, less than one- tenth of Turkish adults with ASD in our sample could work at a job for at least a month. Our results underline the importance of life-long educational and vocational supports for adults with ASD. Further studies should evaluate predictors of gainful employment among this sample. Counseling services, vocational training and supports and coordination of services across schools, families, and potential employers for young adults and adults with ASD should be established as soon as possible in developing countries, including Turkey ${ }^{93-96}$.

An additional indicator of successful functioning in adulthood is independent living which includes separation from the family of origin and becoming socially active in the community. However, studies show that the most adults with ASD continue to live with their parents and never leave home $8,73,78,92,97-103$. Consistent with previous studies, five adults in our sample resided in nursing homes and the majority lived with their families. Transportation is another major problem for adults with ASD. Mobility provides a certain level of independence for young people to travel, access to health care, and attend group activities 104,105 . Those factors have been linked to enhanced quality of life and mental well-being 
106-108; unfortunately, many adults with ASD continue to depend on family members for transportation. The situation may be improving in some countries and in a prior survey from the US, the majority of parents of adolescents with ASD without intellectual disability reported that their children were currently driving (29.0\%) or planning to drive (34.0\%) ${ }^{109}$. Contrasting those results, approximately one percent of our sample could obtain their driver's licence and less than onetenth could travel between cities by using bus/ plane. This discrepancy may reflect the need to address transportation needs of Turkish adults with ASD. Driving instructors and courses may be informed of neurodevelopmental disorders including ASD and appropriate modifications to the licensing process may be required. Staff working at intercity bus/ train/ airplane services may also be educated on the needs of adults with ASD as well as the importance of sensory problems in adapting to travel.

Social relations including friendships protect mental health among people, including adults with ASD. However, adults with autism experience significant difficulties in establishing and maintaining friendships and romantic relationships due to their symptoms ${ }^{110,111}$. Previous studies found that only a small number of adults with ASD could form enduring friendships (romantic/ platonic) ${ }^{38,97,99,112-116}$. Our results are in accordance with those previous reports and we found that parents of just over one-tenth our sample reported their children as having friends and less than five percent experienced romantic relationships.

Previous studies reported that 50.0 to $60.0 \%$ of adults with ASD may be classified as "poor" or "very poor" functioning, while rates of "good" and "very good" functioning are more variable (i.e. 3.0- 48.0\%; 18,38,39,103,117). Rates of favorable outcome may change according to criteria used to define functioning, sampling methods, study centers, enrollment of participants with IDs and presence of social supports. Favorable outcome in those studies was associated with greater IQ levels, early functional language, social reciprocity, better initial functioning and lower levels of ASD symptoms $18,38,39,103,117$. The rate of "good"/ "very good" outcome in our sample was at the lower end of the ranges those previously reported. And differing from those studies, we found that the only predictor of favorable outcome in our sample was the duration of special education received. We could not evaluate the effects of IQ, adaptive functioning at baseline and severity of ASD symptoms due to lack of information in participants' records. Further studies may evaluate these variables on the functionality of adults with ASD in Turkey.

\section{Limitations}

Our study is not without limitations. First, most of the participants could not be contacted/ enrolled in the study, and their medical records were incomplete preventing us from evaluating the effects of baseline IQ, adaptive functioning, ASD symptom severity and effects of specific symptoms. Parents of more impaired adults may refuse participation outright, withdraw their consent or may have moved to other addresses introducing selection bias to our results. Second, we did not evaluate adults with ASD with clinical interviews and depended on the reports of psychiatrists following them for comorbid diagnoses. Further studies may evaluate adults with ASD via specialized instruments (e.g. PAS- ADD etc.). Third, we evaluated depression and caregiving burden among parents with self-reports and there is a possibility of recall and bias in reporting as well as shared method variance. Structured interviews and scales (e.g. Zarit Caregiving Burden Interview, Hamilton Depression Rating Scale etc.) may provide greater objectivity in evaluating those constructs. Fourth, we depended on parents' own reports for their psychopathologies and medical disorders requiring treatment and those reports may also be subject to bias. Last, rather than using discrete questions tapping social participation, we could have used a psychometric scale to evaluate social competence among adults with ASD (e.g. McConkey and Walsh ${ }^{118}$ ). Nevertheless, our study is the first one to evaluate functioning among a large sample of adults with ASD from Turkey along with depression and burnout levels among their parents. Our data may contribute to the literature on adult outcome of ASD as most of the available data are from Western countries. 


\section{Conclusion}

The transition to adulthood is very difficult for individuals with ASD and their families. Similar to the status of education services in other countries, many services that were offered as children are limited or no longer available for adults with ASD in Turkey and there are no structured supports easing transition to adult services ${ }^{10}$. Even in those countries with structured supports to ease transition to adult services, young adults with ASD may be socially isolated and lack participation in the community ${ }^{39,114}$. Lack of education among Health Care Workers (HcWs) for ASD in adulthood may present barriers to receiving help. This may lead to embitterment among parents and adults with ASD $8,20,119$. Our results support the urgent need of a structured transition plan for families of adults with ASD as well as those adults for adult mental health services such as those in other countries (e.g., STEPS) ${ }^{90}$.

Apart from mental health services, governmental and non-governmental (NGO) agencies may facilitate those families in using services for their general medical and social needs, education/ vocational training, housing, transportation, and employment. Turkish HcWs in general settings should be trained in recognition and management of medical comorbidities among adults with ASD especially those with limited communication and the importance of sensory problems limiting compliance with procedures. The majority of the mental health professionals serving adults in Turkey lack training in presentation and management of neurodevelopmental disorders, especially ASD among adults. There is only one clinic dedicated to adults with IDs/ ASD with two additional clinics dedicated to adults with ADHD and all those centers are located only in Istanbul. Those services should be introduced to other cities and regions of Turkey with additional coverage for other neurodevelopmental disorders (e.g., learning disorders, tic disorders, etc.) 97,120 . Psychiatrists and mental health professionals practicing in Turkey and providing care for adults may also be trained to evaluate mutistic patients with ASD as well as those with limited communication skills. Behavioral signs and symptoms of internalizing disorders as well as issues of diagnostic overshadowing may be addressed in those trainings ${ }^{121}$. Special education services for ASD in Turkey are currently focused on academic, social, language and sensory integration skills as well as managing behavior problems and there are limited opportunities to receive vocational training for adolescents/ adults with ASD. Recognizing this gap, the Istanbul Municipality as well as some

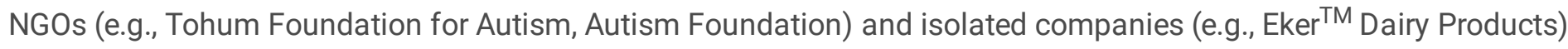
introduced vocational trainings for youth with ASD. A grassroots organization started by Turkish youth with ASD started an online site focused on neurodiversity and reports the problems they face in their daily lives (https://merhabaspektrum.com). However, those attempts lack coordination and need governmental support and planning to achieve nation-wide effects.

As for academic education, the nationwide exams for Turkish high schools and universities may also provide accomodations for youth with ASD. Currently, accomodations are provided only for youth with ADHD and learning disorders. Universities, both private and government affiliated may provide accomodations in classes as well as guidance and counselling on managing life at university especially for freshman classes. Senior students with ASD may be assigned as mentors to first year students and this peer relationship may be beneficial for both parties. Driving licence examinations may be modified for youth with ASD and accomodations to intra- and intercity travel methods may be required. Trainings for train, bus and airplane staff may address problems experienced by those youth. Community participation and increased functioning for adults with ASD required multi-faceted interventions addressing various problems. Our study may be a tentative first step in this direction and the results of our study group should be replicated with a nation-wide survey.

\section{Methods}

\section{Study Centers}

Page $14 / 23$ 
This research was performed in the Child and Adolescent Psychiatry Departments from different geographical regions of Turkey. The diagnoses of included patients at the time of the study were ascertained through clinical interviews by psychiatrists following them at the time as per DSM- $5^{1}$.

\section{Sampling}

Informed consents were obtained from parents of early adults/ late adolescents with ASD as well as verbal individuals with ASD to be included in the study. Inclusion criteria for ASD group were a diagnosis of simplex ASD without known genetic syndromes (i.e. Fragile X syndrome, Down Syndrome, Rett syndrome or variants, etc.) at childhood (i.e. $\leq 12$ years old). The patients in this study involved those who were diagnosed with "infantile autism" or "atypical pervasive developmental disorder" as per DSM-III, "autistic disorder" and "pervasive developmental disorder- not otherwise specified" (PDD-NOS) as per DSM-III-R and "autistic disorder", "Asperger's disorder" and PDD-NOS as per DSM-IV and IVTR criteria. To this end, patients with ICD-10 codes F84.0 (“Childhood Autism”), F84.1 ("Atypical Autism”), F84.5 ("Asperger's Syndrome") and ICD-9 codes 299.0 ("infantile autism") and 299.8 ("other"/ "atypical child psychosis") at the study centers were screened for. From 1057 families, 429 could not be contacted, 297 refused participation in the study and 69 withdrew their consent once enrolled. One patient was found to be diagnosed at 17 years of age and his data were removed from the analysis leaving 261 patients and their parents. Patients with epilepsy and psychiatric or other neurodevelopmental comorbidities were included, and the effects of those confounders were controlled for in analyses.

\section{Ethics}

The study was conducted in accordance with the Declaration of Helsinki and local laws and regulations. The study protocol was approved by the IRB of Gaziantep University (No:2019/234).

\section{Study measures and tools}

\section{Sociodemographic form}

This form was established by the authors for this study and included a questionnaire for both parents which collected information about demographics about the patient and themselves. The questions tapped education status/ level, career, age of diagnosis, history of psychopathology requiring treatment, symptoms observed in the early adult/ late adolescent patients with ASD, developmental milestones, comorbidities (including epilepsy), and past medical history of patients with ASD.

\section{Beck Depression Inventory (BDI)}

The BDI was developed by Beck in 1961 to evaluate symptoms of depression ${ }^{28}$, and a reliability and validity study for the inventory in Turkish was conducted by ${ }^{29}$. This scale includes 21 Likert-type items evaluating motivational, cognitive, somatic, social, and vegetative symptoms of depression. Previous studies on parents of children with disabilities including ASD supported its reliability and validity ${ }^{30-33}$ Parents of adults with ASD completed the BDI in the current study. Cronbach alpha for the present sample was found as 0.79 . Seventeen was taken as the cut-off score for clinically significant depressive symptoms, as suggested in the Turkish reliability and validity study of BDI ${ }^{29}$.

\section{Maslach Burnout Inventory (MBI)}

Page $15 / 23$ 
The MBI, a 22-item Likert-type scale, was developed to evaluate self-reported symptoms of burnout by Maslach and Jackson ${ }^{34}$. It consists of three subscales (emotional exhaustion, depersonalization, and personal accomplishment). MBI was initially translated into Turkish and validated by Ergin ${ }^{35}$. It was later used to evaluate burnout among parents of children with disabilities ${ }^{36}$. In the study by Duygun and Sezgin ${ }^{36}$, factor analysis revealed that a two-factor model was more appropriate for parents and explained $35.6 \%$ of the variance. Accordingly, the items from the depersonalization subscale of the MBI were subsumed under emotional exhaustion, with the personal accomplishment items remaining the same ${ }^{36}$. However a recent study suggested a three factor solution was appropriate ${ }^{37}$ among parents of children with ASD and we used the three factor solution. Mothers and fathers of adults with ASD completed the $\mathrm{MBI}$ in the current study. Cronbach alpha for the present sample was found as 0.74 .

\section{Study Procedure}

Early adults/ late adolescents ( $\geq 18$ years, henceforth termed "adults" for ease of use) diagnosed with ASD were identified by hospital charts. The clinicians completed the sociodemographic form while mothers and fathers of individuals with ASD completed BDI and MBI for themselves.

\section{Statistics}

Data were entered into a database prepared with Statistical Program for Social Sciences (SPSS ${ }^{\mathrm{TM}}$, IBM Inc., Armonk, NY) Version 22.0. Analyses were conducted with SPSS. Nominal data were summarized as counts and frequencies while quantitative data were summarized as means and standard deviations or medians and inter-quartile ranges (IQR) depending on normality and outliers. Comparisons between groups were conducted with chi-square tests for nominal variables. Yates', Fisher's, and Likelihood Ratio corrections were used as appropriate. Bivariate correlations were evaluated using Spearman correlation analyses. Bivariate comparisons of quantitative variables between independent and dependent groups were conducted with t tests. Predictors of "good"/ "very good" functioning in adulthood were evaluated with logistic regression (enter method). P was set at 0.05 (two-tailed). Bonferroni- Holm correction for controlling family-wise error was used in bivariate analyses of associated factors for parental depression and burnout (p', Gaetano, J. (2018). Holm-Bonferroni sequential correction: An Excel calculator (1.3) [Microsoft Excel workbook]. Retrieved from:

https://www.researchgate.net/publication/322568540_HolmBonferroni_sequential_correction_An_Excel_calculator_13). Effect sizes for significant findings were also reported.

\section{Declarations}

\section{Acknowledgements:}

We would like to thank to Burcu Gonul who is the secretary of Child and Adolescent Psychiatry department at Dr. Turgut Noyan Medical and Research Center in Adana/Turkey for her supperhuman support for the overall coordination of the whole study and also thank to all families, individiuals with ASDs to be with us in this research.

\section{Author contributions:}

MOK, AET, FK and CG conceived and designed the study. MOK wrote the article with contribution from AET, FK, SAG, NI and ESE. AET conducted preliminary data processing and analysed the data. MOK, AET, FK, PV, CG, BK, GÖ, TM, EYA, FHÖ, ENP, ŞÇY, MK, ZT, ÇB, NŞ, ÖB, HK, TES, SBA, GGA, PD, FT, CM, ÖK, BK, SK, ED, SÖ, LS, YSK, ÜI, EA, HA, ÇY, BPT, AB, MAC, HÖ, ŞE, HAT, EA, OK took part in the data collection process. All authors read and approved the final manuscript. No conflict of interest was declared by the authors

\section{Funding:}


This research received no specific grant from any funding agency in the public, commercial, or not-for-profit sectors.

\section{Declaration of conflicting interests:}

None

\section{References}

1. American Psychiatric Association, A. Diagnostic and Statistical Manual of Mental Disorders- Fifth Edition. (DSM-5). (American Psychiatric Publishing, 2013).

2. Bhandari, R., Paliwal, J. K. \& Kuhad, A. Neuropsychopathology of Autism Spectrum Disorder: Complex Interplay of Genetic, Epigenetic, and Environmental Factors. Adv Neurobio/ 24, 97-141, doi:10.1007/978-3-030-30402-7_4 (2020).

3. Manoli, D. S. \& State, M. W. Autism Spectrum Disorder Genetics and the Search for Pathological Mechanisms. Am J Psychiatry 178, 30-38, doi:10.1176/appi.ajp.2020.20111608 (2021).

4. Xu, G. et al. Prevalence and Treatment Patterns of Autism Spectrum Disorder in the United States, 2016. JAMA Pediatr, 173(2), 153-159. https://doi.org/10.1001/jamapediatrics.2018.4208 (2019).

5. Chiarotti, F. \& Venerosi, A. Epidemiology of Autism Spectrum Disorders: A Review of Worldwide Prevalence Estimates Since 2014. Brain Sci 10, doi:10.3390/brainsci10050274 (2020).

6. Christensen, D. L. et al. Prevalence and Characteristics of Autism Spectrum Disorder Among Children Aged 4 Years - Early Autism and Developmental Disabilities Monitoring Network, Seven Sites, United States, 2010, 2012, and 2014. MMWR Surveill Summ 68, 1-19, doi:10.15585/mmwr.ss6802a1 (2019).

7. Piven, J., Rabins, P. \& Autism-in-Older Adults Working, G. Autism spectrum disorders in older adults: toward defining a research agenda. J Am Geriatr Soc 59, 2151-2155, doi:10.1111/j.1532-5415.2011.03632.x (2011).

8. Chamak, B. \& Bonniau, B. Trajectories, Long-Term Outcomes and Family Experiences of 76 Adults with Autism Spectrum Disorder. J Autism Dev Disord 46, 1084-1095, doi:10.1007/s10803-015-2656-6 (2016).

9. Wisner-Carlson, R., Uram, S. \& Flis, T. The Transition to Adulthood for Young People with Autism Spectrum Disorder. Psychiatr Clin North Am 43, 673-686, doi:10.1016/j.psc.2020.08.005 (2020).

10. Elster, N. \& Parsi, K. Transitioning from Adolescence to Adulthood with Autism Spectrum Disorder: An Overview of Planning and Legal Issues. Psychiatr Clin North Am 43, 723-733, doi:10.1016/j.psc.2020.08.008 (2020).

11. Lai, M. C., Lombardo, M. V. \& Baron-Cohen, S. Autism. Lancet 383, 896-910, doi:10.1016/S0140-6736(13)61539-1 (2014).

12. Van Bourgondien, M. E., Dawkins, T. \& Marcus, L. Families of adults with autism spectrum disorders. 15-40 (Springer, 2014).

13. Blacher, J., Kraemer, B. \& Howell, E. Family expectations and transition experiences for young adults with severe disabilities: does syndrome matter? Advances in Mental Health and Learning Disabilities 4, 3-16, doi:10.5042/amhld.2010.0052 (2010).

14. Bujnowska, A. M., Rodriguez, C., Garcia, T., Areces, D. \& Marsh, N. V. Parenting and Future Anxiety: The Impact of Having a Child with Developmental Disabilities. Int J Environ Res Public Health 16, doi:10.3390/ijerph16040668 (2019).

15. Gray, D. E. Ten years on: A longitudinal study of families of children with autism. Journal of Intellectual and Developmental Disability 27, 215-222, doi:10.1080/1366825021000008639 (2002).

16. Burke, M. \& Heller, T. Individual, parent and social-environmental correlates of caregiving experiences among parents of adults with autism spectrum disorder. J Intellect Disabil Res 60, 401-411, doi:10.1111/jir.12271 (2016). 
17. Lounds, J., Seltzer, M. M., Greenberg, J. S. \& Shattuck, P. T. Transition and change in adolescents and young adults with autism: longitudinal effects on maternal well-being. Am J Ment Retard 112, 401-417, doi:10.1352/08958017(2007)112[401:TACIAA]2.0.C0;2 (2007).

18. Simonoff, E. et al. Trajectories in Symptoms of Autism and Cognitive Ability in Autism From Childhood to Adult Life: Findings From a Longitudinal Epidemiological Cohort. J Am Acad Child Adolesc Psychiatry 59, 1342-1352, doi:10.1016/j.jaac.2019.11.020 (2020).

19. Wong, V., McGrew, J. \& Ruble, L. Predicting the Outcomes of Parents of Transition-Age Youth or Young Adults with ASD. J Autism Dev Disord 50, 2723-2739, doi:10.1007/s10803-020-04362-1 (2020).

20. Hoyle, J. N., Laditka, J. N. \& Laditka, S. B. Mental health risks of parents of children with developmental disabilities: A nationally representative study in the United States. Disabil Health J, 101020, doi:10.1016/j.dhjo.2020.101020 (2020).

21. Atbasoglu, E. C. Autism Spectrum Disorder as an Initial Diagnosis in Adults. Noro Psikiyatr Ars 57, 1-2, doi:10.29399/npa.25050 (2020).

22. Agirman, A. Autism Spectrum Disorder: Comorbid psychotic symptoms and comparison with schizophrenia. Unpublished Dissertation Ph.D. thesis, (2010).

23. Kücük, A., Maner, F. \& Ceylan, M. E. Autism spectrum disorders among adolescents and adults and comparison with schizophrenia. The European Research Journal 5, 962-968, doi:10.18621/eurjç441214 (2019).

24. Gormez, A. Family Caregiving Burden of Adults with Intellectual Disability and Associated Factors. Anatol Clin 22, 169-176, doi:10.21673/anadoluklin.327742 (2017).

25. Gormez, A. et al. Psychiatric symptoms, challenging behaviour and utilization of psychiatric services among adults with intellectual disabilities in Turkey. J Appl Res Intellect Disabil 33, 1038-1048, doi:10.1111/jar.12726 (2020).

26. Barrett, E. et al. The child and adolescent psychiatry: study of training in Europe (CAP-STATE). Eur Child Adolesc Psychiatry 29, 11-27, doi:10.1007/s00787-019-01416-3 (2020).

27. Clausen, C. E. et al. Child and adolescent psychiatry training and services in the Middle East region: a current status assessment. Eur Child Adolesc Psychiatry 29, 51-61, doi:10.1007/s00787-019-01360-2 (2020).

28. Beck T, A., Steer A, R. \& Carbin G, M. Psychometric properties of the Beck Depression Inventory: Twenty-five years of evaluation. Clinical Psychology Review 8, 77-100, doi:doi.org/10.1016/0272-7358(88)90050-5 (1988).

29. Hisli, N. Reliability and validity of the Turkish version of Beck Depression Inventory among college students. Turkish Journal of Psychology 7, 3-13 (1989).

30. Baykal, S., Karakurt, M. N., Cakir, M. \& Karabekiroglu, K. An Examination of the Relations Between Symptom Distributions in Children Diagnosed with Autism and Caregiver Burden, Anxiety and Depression Levels. Community Ment Health J 55, 311-317, doi:10.1007/s10597-018-0343-8 (2019).

31. Tekinarslan, I. C. A comparison study of depression and quality of life in Turkish mothers of children with Down syndrome, cerebral palsy, and autism spectrum disorder. Psychological Reports 112, 266-287 (2013).

32. Kutuk, M. O. et al. High Depression Symptoms and Burnout Levels Among Parents of Children with Autism Spectrum Disorders: A Multi-Center, Cross-Sectional, Case-Control Study. J Autism Dev Disord, doi:10.1007/s10803021-04874-4 (2021).

33. Yıldız, A., Tarakcı, D., Hajebrahimi, F. \& Mutluay, F. Disabled children's functionality and maternal quality of life and psychological status. Pediatrics International 58, 1291-1296 (2016).

34. Maslach, C. \& Jackson, S. E. The measurement of experienced burnout. Journal of organizational behavior 2, 99113 (1981).

35. Ergin, C. in Ankara: VII. National Psychology Congress. 143-144.

Page $18 / 23$ 
36. Duygun, T. \& Sezgin, N. The Effects of Stress Symptoms, Coping Styles and Perceived Social Support on Burnout Level of Mentally Handicapped and Healthy Children's Mothers. Turkish Journal of Psychology 18, $37-52$ (2003).

37. Semerci, B., Comert, I. T. \& Tuncel, A. Determining Maslach Burnout Inventory usability of parents of autistic spectrum disorder children. (2018).

38. Howlin, P., Goode, S., Hutton, J. \& Rutter, M. Adult outcome for children with autism. J Child Psychol Psychiatry 45, 212-229, doi:10.1111/j.1469-7610.2004.00215.x (2004).

39. Howlin, P., Moss, P., Savage, S. \& Rutter, M. Social outcomes in mid- to later adulthood among individuals diagnosed with autism and average nonverbal IQ as children. J Am Acad Child Adolesc Psychiatry 52, 572-581 e571, doi:10.1016/j.jaac.2013.02.017 (2013).

40. Levy, S. E., Mandell, D. S. \& Schultz, R. T. Autism. Lancet 374, 1627-1638, doi:10.1016/S0140-6736(09)61376-3 (2009).

41. Nicolaidis, C., Kripke, C. C. \& Raymaker, D. Primary care for adults on the autism spectrum. Med Clin North Am 98, 1169-1191, doi:10.1016/j.mcna.2014.06.011 (2014).

42. Nicolaidis, C. et al. Creating Accessible Survey Instruments for Use with Autistic Adults and People with Intellectual Disability: Lessons Learned and Recommendations. Autism Adulthood 2, 61-76, doi:10.1089/aut.2019.0074 (2020).

43. McStay, R. L., Trembath, D. \& Dissanayake, C. Maternal stress and family quality of life in response to raising a child with autism: from preschool to adolescence. Res Dev Disabil 35, 3119-3130, doi:10.1016/j.ridd.2014.07.043 (2014).

44. Scherer, N., Verhey, I. \& Kuper, H. Depression and anxiety in parents of children with intellectual and developmental disabilities: A systematic review and meta-analysis. PLoS One 14, e0219888, doi:10.1371/journal.pone.0219888 (2019).

45. Ceylan, R. \& Aral, N. An examination of the correlation between depression and hopelessness levels in mothers of disabled children. Soc Behav Pers 35, 903-908 (2007).

46. Kilincaslan, A. et al. Daily living skills in children with autism spectrum disorder and intellectual disability: A comparative study from Turkey. Res Dev Disabil 85, 187-196, doi:10.1016/j.ridd.2018.12.005 (2019).

47. Kuru, N. \& Piyal, B. Perceived social support and quality of life of parents of children with Autism. Niger J Clin Pract 21, 1182-1189, doi:10.4103/njcp.njcp_13_18 (2018).

48. Ozgur, B. G., Aksu, H. \& Eser, E. Factors affecting quality of life of caregivers of children diagnosed with autism spectrum disorder. Indian J Psychiatry 60, 278-285, doi:10.4103/psychiatry.IndianJPsychiatry_300_17 (2018).

49. Hartley, S. L., Papp, L. M. \& Bolt, D. Spillover of Marital Interactions and Parenting Stress in Families of Children With Autism Spectrum Disorder. J Clin Child Adolesc Psychol 47, S88-S99, doi:10.1080/15374416.2016.1152552 (2018).

50. Chan, K. K. S. \& Leung, D. C. K. The Impact of Child Autistic Symptoms on Parental Marital Relationship: Parenting and Coparenting Processes as Mediating Mechanisms. Autism Res, doi:10.1002/aur.2297 (2020).

51. Cohrs, A. C. \& Leslie, D. L. Depression in Parents of Children Diagnosed with Autism Spectrum Disorder: A ClaimsBased Analysis. J Autism Dev Disord 47, 1416-1422, doi:10.1007/s10803-017-3063-y (2017).

52. Hickey, E. J., Hartley, S. L. \& Papp, L. Psychological Well-Being and Parent-Child Relationship Quality in Relation to Child Autism: An Actor-Partner Modeling Approach. Fam Process 59, 636-650, doi:10.1111/famp.12432 (2020).

53. Schnabel, A. et al. Psychopathology in parents of children with autism spectrum disorder: A systematic review and meta-analysis of prevalence. Autism 24, 26-40, doi:10.1177/1362361319844636 (2020). 
54. Walton, K. M. \& Tiede, G. Brief report: Does "healthy" family functioning look different for families who have a child with autism? Res Autism Spectr Disord 72, doi:10.1016/j.rasd.2020.101527 (2020).

55. Jokiranta-Olkoniemi, E. et al. Risk for Premature Mortality and Intentional Self-harm in Autism Spectrum Disorders. J Autism Dev Disord, doi:10.1007/s10803-020-04768-x (2020).

56. Lever, A. G. \& Geurts, H. M. Psychiatric Co-occurring Symptoms and Disorders in Young, Middle-Aged, and Older Adults with Autism Spectrum Disorder. J Autism Dev Disord 46, 1916-1930, doi:10.1007/s10803-016-2722-8 (2016).

57. Moseley, R. L., Gregory, N. J., Smith, P., Allison, C. \& Baron-Cohen, S. Links between self-injury and suicidality in autism. Mol Autism 11, 14, doi:10.1186/s13229-020-0319-8 (2020).

58. Pandina, G., Ring, R. H., Bangerter, A. \& Ness, S. Current Approaches to the Pharmacologic Treatment of Core Symptoms Across the Lifespan of Autism Spectrum Disorder. Child Adolesc Psychiatr Clin N Am 29, 301-317, doi:10.1016/j.chc.2019.12.004 (2020).

59. Lake, J. K., Balogh, R. \& Lunsky, Y. Polypharmacy profiles and predictors among adults with autism spectrum disorders, Research in Autism. Spectrum Disorders 6, 1142-1149, doi:10.1016/j.rasd.2012.03.005 (2012).

60. Foley, K. R. \& Trollor, J. Management of mental ill health in people with autism spectrum disorder. Aust Fam Physician 44, 784-790 (2015).

61. Kerns, C. M. et al. Brief measures of anxiety in non-treatment-seeking youth with autism spectrum disorder. Autism 19, 969-979, doi:10.1177/1362361314558465 (2015).

62. Stewart, M. E., Barnard, L., Pearson, J., Hasan, R. \& O'Brien, G. Presentation of depression in autism and Asperger syndrome: a review. Autism 10, 103-116, doi:10.1177/1362361306062013 (2006).

63. Berthoz, S., Lalanne, C., Crane, L. \& Hill, E. L. Investigating emotional impairments in adults with autism spectrum disorders and the broader autism phenotype. Psychiatry Res 208, 257-264, doi:10.1016/j.psychres.2013.05.014 (2013).

64. Ghaziuddin, M., Ghaziuddin, N. \& Greden, J. Depression in persons with autism: implications for research and clinical care. J Autism Dev Disord 32, 299-306, doi:10.1023/a:1016330802348 (2002).

65. Morgan, C., Roy, M. \& Chance, P. Psychiatric comorbidity and medication use in autism: A community survey. Psychiatric Bulletin 27, 378-381, doi:10.1192/pb.27.10.378 (2003).

66. Hull, L. et al. "Putting on My Best Normal": Social Camouflaging in Adults with Autism Spectrum Conditions. $J$ Autism Dev Disord 47, 2519-2534, doi:10.1007/s10803-017-3166-5 (2017).

67. de Bruin, E. I., Ferdinand, R. F., Meester, S., de Nijs, P. F. \& Verheij, F. High rates of psychiatric co-morbidity in PDDNOS. J Autism Dev Disord 37, 877-886, doi:10.1007/s10803-006-0215-x (2007).

68. Frazier, J. A. et al. Should the diagnosis of Attention-Deficit/ Hyperactivity disorder be considered in children with Pervasive Developmental Disorder? Journal of Attention Disorders 4, 203-211, doi:10.1177/108705470100400402 (2001).

69. Goldstein, S. \& Schwebach, A. J. The comorbidity of Pervasive Developmental Disorder and Attention Deficit Hyperactivity Disorder: results of a retrospective chart review. J Autism Dev Disord 34, 329-339, doi:10.1023/b:jadd.0000029554.46570.68 (2004).

70. Joshi, G. et al. The heavy burden of psychiatric comorbidity in youth with autism spectrum disorders: a large comparative study of a psychiatrically referred population. J Autism Dev Disord 40, 1361-1370, doi:10.1007/s10803-010-0996-9 (2010).

71. Lee, D. O. \& Ousley, O. Y. Attention-deficit hyperactivity disorder symptoms in a clinic sample of children and adolescents with pervasive developmental disorders. J Child Adolesc Psychopharmacol 16, 737-746, 
doi:10.1089/cap.2006.16.737 (2006).

72. Yoshida, Y. \& Uchiyama, T. The clinical necessity for assessing Attention Deficit/Hyperactivity Disorder (AD/HD) symptoms in children with high-functioning Pervasive Developmental Disorder (PDD). Eur Child Adolesc Psychiatry 13, 307-314, doi:10.1007/s00787-004-0391-1 (2004).

73. Billstedt, E., Gillberg, I. C. \& Gillberg, C. Autism after adolescence: population-based 13- to 22-year follow-up study of 120 individuals with autism diagnosed in childhood. J Autism Dev Disord 35, 351-360, doi:10.1007/s10803-0053302-5 (2005).

74. Bryson, S. E. \& Smith, I. M. Epidemiology of autism: Prevalence, associated characteristics, and implications for research and service delivery. Mental Retardation and Developmental Disabilities Research Reviews 4, 97-103, doi:https://doi.org/10.1002/(SICI)1098-2779(1998)4:2<97::AID-MRDD6>3.0.C0;2-U (1998).

75. Bennett, A. E., Miller, J. S., Stollon, N., Prasad, R. \& Blum, N. J. Autism Spectrum Disorder and Transition-Aged Youth. Curr Psychiatry Rep 20, 103, doi:10.1007/s11920-018-0967-y (2018).

76. Broder-Fingert, S., Brazauskas, K., Lindgren, K., lannuzzi, D. \& Van Cleave, J. Prevalence of overweight and obesity in a large clinical sample of children with autism. Acad Pediatr 14, 408-414, doi:10.1016/j.acap.2014.04.004 (2014).

77. Croen, L. A. et al. The health status of adults on the autism spectrum. Autism 19, 814-823, doi:10.1177/1362361315577517 (2015).

78. Eaves, L. C. \& Ho, H. H. Young adult outcome of autism spectrum disorders. J Autism Dev Disord 38, 739-747, doi:10.1007/s10803-007-0441-x (2008).

79. Fortuna, R. J. et al. Health Conditions and Functional Status in Adults with Autism: A Cross-Sectional Evaluation. $J$ Gen Intern Med 31, 77-84, doi:10.1007/s11606-015-3509-x (2016).

80. Jones, K. B. et al. A description of medical conditions in adults with autism spectrum disorder: A follow-up of the 1980s Utah/UCLA Autism Epidemiologic Study. Autism 20, 551-561, doi:10.1177/1362361315594798 (2016).

81. Tyler, C. V., Schramm, S. C., Karafa, M., Tang, A. S. \& Jain, A. K. Chronic disease risks in young adults with autism spectrum disorder: forewarned is forearmed. Am J Intellect Dev Disabil 116, 371-380, doi:10.1352/1944-7558116.5.371 (2011).

82. Lecavalier, L. et al. An exploration of concomitant psychiatric disorders in children with autism spectrum disorder. Compr Psychiatry 88, 57-64, doi:10.1016/j.comppsych.2018.10.012 (2019).

83. Mannion, A., Leader, G. \& Healy, O. An investigation of comorbid psychological disorders, sleep problems, gastrointestinal symptoms and epilepsy in children and adolescents with autism spectrum disorder. Res Autism Spectr Disord 7, 35-42 (2013).

84. Besag, F. M. Epilepsy in patients with autism: links, risks and treatment challenges. Neuropsychiatr Dis Treat 14, 110, doi:10.2147/NDT.S120509 (2018).

85. Danielsson, S., Gillberg, I. C., Billstedt, E., Gillberg, C. \& Olsson, I. Epilepsy in young adults with autism: a prospective population-based follow-up study of 120 individuals diagnosed in childhood. Epilepsia 46, 918-923, doi:10.1111/j.1528-1167.2005.57504.x (2005).

86. Jeste, S. S. \& Tuchman, R. Autism Spectrum Disorder and Epilepsy: Two Sides of the Same Coin? J Child Neurol 30, 1963-1971, doi:10.1177/0883073815601501 (2015).

87. Tuchman, R. \& Rapin, I. Epilepsy in autism. Lancet Neurol 1, 352-358, doi:10.1016/s1474-4422(02)00160-6 (2002).

88. Howlin, P. \& Moss, P. Adults with autism spectrum disorders. Can J Psychiatry 57, 275-283, doi:10.1177/070674371205700502 (2012).

Page $21 / 23$ 
89. Poon, K. K. \& Sidhu, D. J. Adults with autism spectrum disorders: a review of outcomes, social attainment, and interventions. Curr Opin Psychiatry 30, 77-84, doi:10.1097/YC0.0000000000000306 (2017).

90. White, S. W. et al. Development of a College Transition and Support Program for Students with Autism Spectrum Disorder. J Autism Dev Disord 47, 3072-3078, doi:10.1007/s10803-017-3236-8 (2017).

91. Ballaban-Gil, K., Rapin, I., Tuchman, R. \& Shinnar, S. Longitudinal examination of the behavioral, language, and social changes in a population of adolescents and young adults with autistic disorder. Pediatr Neurol 15, 217-223, doi:10.1016/s0887-8994(96)00219-6 (1996).

92. Gray, K. M. et al. Adult outcomes in autism: community inclusion and living skills. J Autism Dev Disord 44, 30063015, doi:10.1007/s10803-014-2159-x (2014).

93. Howlin, P., Alcock, J. \& Burkin, C. An 8 year follow-up of a specialist supported employment service for high-ability adults with autism or Asperger syndrome. Autism 9, 533-549, doi:10.1177/1362361305057871 (2005).

94. Shattuck, P. T. et al. Services for adults with an autism spectrum disorder. Can J Psychiatry 57, 284-291, doi:10.1177/070674371205700503 (2012).

95. Wehman, P. et al. Employment for adults with autism spectrum disorders: A retrospective review of a customized employment approach. Res Dev Disabil 53-54, 61-72, doi:10.1016/j.ridd.2016.01.015 (2016).

96. Wehman, P. et al. Effects of an employer-based intervention on employment outcomes for youth with significant support needs due to autism. Autism 21, 276-290, doi:10.1177/1362361316635826 (2017).

97. Barnard, J., Harvey, V., Potter, D. \& Prior, A. Ignored or ineligible? The reality for adults with autism spectrum disorders. (The National Autistic Society, 2001).

98. Ellison, D., Clark, C. \& Langford, B. in Presented at IMFAR.

99. Engstrom, I., Ekstrom, L. \& Emilsson, B. Psychosocial functioning in a group of Swedish adults with Asperger syndrome or high-functioning autism. Autism 7, 99-110, doi:10.1177/1362361303007001008 (2003).

100. Esbensen, A. J., Bishop, S., Seltzer, M. M., Greenberg, J. S. \& Taylor, J. L. Comparisons between individuals with autism spectrum disorders and individuals with Down syndrome in adulthood. Am J Intellect Dev Disabil 115, 277290, doi:10.1352/1944-7558-115.4.277 (2010).

101. Farley, M. et al. Mid-life social outcomes for a population-based sample of adults with ASD. Autism Res 11, 142152, doi:10.1002/aur.1897 (2018).

102. Farley, M. A. et al. Twenty-year outcome for individuals with autism and average or near-average cognitive abilities. Autism Res 2, 109-118, doi:10.1002/aur.69 (2009).

103. Howlin, P. Outcome in Adult Life for more Able Individuals with Autism or Asperger Syndrome. Autism 4, 63-83, doi:10.1177/1362361300004001005 (2000).

104. Curry, A. E., Yerys, B. E., Huang, P. \& Metzger, K. B. Longitudinal study of driver licensing rates among adolescents and young adults with autism spectrum disorder. Autism 22, 479-488, doi:10.1177/1362361317699586 (2018).

105. Winston, F. K. \& Senserrick, T. M. Competent independent driving as an archetypal task of adolescence. Inj Prev 12 Suppl 1, i1-3, doi:10.1136/ip.2006.012765 (2006).

106. Dickerson, A. E. et al. Transportation and aging: a research agenda for advancing safe mobility. Gerontologist 47, 578-590, doi:10.1093/geront/47.5.578 (2007).

107. Fonda, S. J., Wallace, R. B. \& Herzog, A. R. Changes in driving patterns and worsening depressive symptoms among older adults. J Gerontol B Psychol Sci Soc Sci 56, S343-351, doi:10.1093/geronb/56.6.s343 (2001).

108. Taylor, J. L., Smith, L. E. \& Mailick, M. R. Engagement in vocational activities promotes behavioral development for adults with autism spectrum disorders. J Autism Dev Disord 44, 1447-1460, doi:10.1007/s10803-013-2010-9 (2014). 
109. Huang, P., Kao, T., Curry, A. E. \& Durbin, D. R. Factors associated with driving in teens with autism spectrum disorders. J Dev Behav Pediatr 33, 70-74, doi:10.1097/DBP.0b013e31823a43b7 (2012).

110. Mazurek, M. O. Loneliness, friendship, and well-being in adults with autism spectrum disorders. Autism 18, 223232, doi:10.1177/1362361312474121 (2014).

111. Rotheram-Fuller, E., Kasari, C., Chamberlain, B. \& Locke, J. Social involvement of children with autism spectrum disorders in elementary school classrooms. J Child Psychol Psychiatry 51, 1227-1234, doi:10.1111/j.14697610.2010.02289.x (2010).

112. Billstedt, E., Gillberg, I. C. \& Gillberg, C. Aspects of quality of life in adults diagnosed with autism in childhood: a population-based study. Autism 15, 7-20, doi:10.1177/1362361309346066 (2011).

113. Liptak, G. S., Kennedy, J. A. \& Dosa, N. P. Social participation in a nationally representative sample of older youth and young adults with autism. J Dev Behav Pediatr 32, 277-283, doi:10.1097/DBP.0b013e31820b49fc (2011).

114. Magiati, I., Tay, X. W. \& Howlin, P. Cognitive, language, social and behavioural outcomes in adults with autism spectrum disorders: a systematic review of longitudinal follow-up studies in adulthood. Clin Psychol Rev 34, 73-86, doi:10.1016/j.cpr.2013.11.002 (2014).

115. Orsmond, G. I., Krauss, M. W. \& Seltzer, M. M. Peer relationships and social and recreational activities among adolescents and adults with autism. J Autism Dev Disord 34, 245-256, doi:10.1023/b:jadd.0000029547.96610.df (2004).

116. Whitehouse, A. J., Watt, H. J., Line, E. A. \& Bishop, D. V. Adult psychosocial outcomes of children with specific language impairment, pragmatic language impairment and autism. Int J Lang Commun Disord 44, 511-528, doi:10.1080/13682820802708098 (2009).

117. Stringer, D. et al. Trajectories of emotional and behavioral problems from childhood to early adult life. Autism 24, 1011-1024, doi:10.1177/1362361320908972 (2020).

118. McConkey, R. \& Walsh, J. An index of social competence for use in determining the service needs of mentally handicapped adults. J Ment Defic Res 26, 47-61, doi:10.1111/j.1365-2788.1982.tb00128.x (1982).

119. Camm-Crosbie, L., Bradley, L., Shaw, R., Baron-Cohen, S. \& Cassidy, S. 'People like me don't get support': Autistic adults' experiences of support and treatment for mental health difficulties, self-injury and suicidality. Autism 23, 1431-1441, doi:10.1177/1362361318816053 (2019).

120. Lai, M. C. \& Baron-Cohen, S. Identifying the lost generation of adults with autism spectrum conditions. Lancet Psychiatry 2, 1013-1027, doi:10.1016/S2215-0366(15)00277-1 (2015).

121. Nylander, L. \& Gillberg, C. Screening for autism spectrum disorders in adult psychiatric out-patients: a preliminary report. Acta Psychiatrica Scandinavica 103, 428-434 (2001). 